\title{
Tylosin exposure reduces the susceptibility of Salmonella Typhimurium to florfenicol and tetracycline
}

\author{
Abraham Fikru Mechesso and Seung-Chun Park
}

\begin{abstract}
Background: Antibiotics exposure has been implicated in the emergence of bacterial strains that are resistant to structurally related or unrelated antibiotics. Tylosin is a macrolide antibiotic that has been administered to treat respiratory pathogenic bacteria in swine. Thus, this study was undertaken to evaluate the impact of exposure to a constant $(3 \mu \mathrm{g} / \mathrm{mL})$ and decreasing concentrations of tylosin on the susceptibility of Salmonella enterica serovar Typhimurium to various antibiotics.

Results: S. Typhimurium strains exposed to tylosin for 12 and $24 \mathrm{~h}$ in the in vitro dynamic model demonstrated at least an eight-fold increase in the minimum inhibitory concentrations (MICs) of florfenicol and tetracycline. Exposure to tylosin extended the lag-time of the growth curve and enhanced the generation of reactive oxygen species. Gene expression analysis demonstrated up-regulation of the acrAB and to/C Salmonella efflux pump genes and its global regulators (marA and soxS). Besides, the expression of ompC gene was down-regulated in tylosin exposed $S$. Typhimurium.
\end{abstract}

Conclusion: Exposure to decreasing concentrations of tylosin could reduce the susceptibility of S. Typhimurium to florfenicol and tetracycline.

Keywords: Florfenicol, S. Typhimurium, Susceptibility, Tetracycline, Tylosin

\section{Background}

Multidrug-resistant strains of Salmonella enterica serovar Typhimurium have become a major concern in both veterinary and human medicine. It is one of the main causes of food-borne gastroenteritis in humans [1]. Swine are asymptomatic carriers of $S$. Typhimurium and serve as reservoirs of infection [2]. Although infection is usually associated with self-limiting gastroenteritis, septicaemic cases associated with severe clinical signs and sudden death have been reported in swine [3].

Tylosin is mainly used to control respiratory infections caused by Gram-positive bacteria and Mycoplasma species in farm animals including swine. Although it is prohibited in Europe and some Asian countries, it has been used as a livestock feed additive and antibiotic growth promoter in other parts of the world $[4,5]$. Sub-

\footnotetext{
* Correspondence: parksch@knu.ac.kr

Laboratory of Veterinary Pharmacokinetics and Pharmacodynamics, College of Veterinary Medicine, Kyungpook National University, Bukgu, Daegu 41566, South Korea
}

inhibitory concentrations of antibiotics have been reported to induce the emergence of antibiotic resistance [6]. Studies have shown the emergence of antibioticresistant bacteria following prior exposure to subtherapeutic doses of structurally related or unrelated antibiotic (s). Aarestrup and Carstensen [7] have demonstrated that the use of tylosin as a growth promoter in pigs contributed to the emergence of resistant enterococci and Staphylococcus hyicus. A study by Fung-Tomc et al. [8] revealed that pre-exposure of methicillinresistant Staphylococcus aureus and Pseudomonas aeruginosa to sub-inhibitory concentrations of ciprofloxacin resulted in resistance to structurally unrelated antibiotics, including tetracycline and gentamicin. In addition, exposure to sub-inhibitory concentrations of kanamycin and streptomycin is reported to induce resistance to structurally unrelated antibiotics in Streptococcus pneumoniae and Escherichia coli $[9,10]$.

Despite the widespread uses of tylosin in the livestock industry, especially swine, there is no report on 
the impacts of tylosin exposure on the antibiotic susceptibility profiles of Gram-negative bacteria including $S$. Typhimurium. In this study, we attempted to examine the impacts of exposure to a constant $(3 \mu \mathrm{g} /$ $\mathrm{mL}$ ) and decreasing concentrations of tylosin on the susceptibilities of $S$. Typhimurium strains to selected antibiotics that are commonly used in veterinary medicine. We have also determined the tylosininduced changes in the gene expression of $S$. Typhimurium efflux pump and outer membrane porins.

\section{Results}

\section{Effects of tylosin exposure on the susceptibility of $S$. Typhimurium}

The MICs of the selected antibiotics against $S$. Typhimurium strains before and after exposure to tylosin in the dynamic model (taken after 12 and $24 \mathrm{~h}$ of incubation) and in the presence (EI) and absence (WEI) of Phe-Arg- $\beta$-naphthylamide (an efflux pump inhibitor) is summarized in Table 1. Non-exposed strains of $S$. Typhimurium LVPP-STI2 and LVPP-STI15 were resistant to sulfamethoxazole and streptomycin while trimethoprim and tetracycline resistance was observed only in S. Typhimurium LVPP-STI15. Tylosin exposed S. Typhimurium ATCC 14028 and LVPP-STI2 demonstrated higher MICs of florfenicol and tetracycline (by at least 8-fold) compared to the non-exposed counterparts. However, exposure did not change the MICs of florfenicol and tetracycline in S. Typhimurium LVPP-STI15. The tylosin-induced increase in the MICs of florfenicol and tetracycline were reduced to various levels in the presence of Phe-Arg- $\beta$-naphthylamide. In contrast, exposure of $S$. Typhimurium strains to tylosin in the dynamic model did not cause a significant change in the MICs of marbofloxacin, streptomycin, sulfamethoxazole and trimethoprim. Similarly, exposure to tylosin for 1, 2, 4 , and $8 \mathrm{~h}$ in the dynamic model and at all-time points in the static model demonstrated slight or no change in the MICs of the tested antibiotics (Additional file 1). Therefore, $S$. Typhimurium strains that were exposed to tylosin for $12 \mathrm{~h}$ in the dynamic model were considered for subsequent experiments.

\section{Growth curves of $S$. Typhimurium}

Figure 1 shows the growth curves of $S$. Typhimurium strains before and after exposure to tylosin in the dynamic model. The duration of lag-time in tylosin exposed S. Typhimurium strains ATCC 14028 and LVPP-STI2 were longer $(\sim 4.5 \mathrm{~h})$ than the non-exposed counterparts $(\sim 1.5-2 \mathrm{~h})$. Treatment with tylosin extended the lag-time of $S$. Typhimurium LVPP-STI15 only by approximately $1.5 \mathrm{~h}$. However, once the strains reached stationary phase $(\sim 10 \mathrm{~h})$; the differences were negligible.

Tylosin-induced free radical generation in S. Typhimurium In the Nitro blue tetrazolium (NBT) assay, the extent of free radicals generated in tylosin exposed $S$. Typhimurium ATCC 14028 and LVPP-STI 2 were significantly higher $(P<0.01)$ compared to its counterparts before exposure (Fig. 2). However, tylosin did not cause a significant change in free radical generation in $S$. Typhimurium LVPP-STI15.

\section{Effects of tylosin treatment on S. Typhimurium efflux- pump and outer membrane proteins}

Figure 3(a-f) shows the role of tylosin on the gene expression of $a c r A, a c r B$, and $\operatorname{tol} C$, and the $\operatorname{mar} A$, soxS, and $\operatorname{ram} A$ genes encoding their global regulators. Treatment with tylosin significantly increased the gene expression of acr A, acrB and tolC by 8.6-to- 10.2 fold $(P<0.001), 3.3$-to4.5 fold $(P<0.05)$, and 1.7 -to-3.1 fold $(P<0.05)$, respectively relative to the non-exposed counterparts. Similarly, tylosin treated $S$. Typhimurium strains demonstrated 5.2-

Table 1 The MICs $(\mu \mathrm{g} / \mathrm{mL}$ ) of the selected antibiotics against S. Typhimurium strains before and after exposure to tylosin (taken after 12 and $24 \mathrm{~h}$ of incubation) in the in vitro dynamic model and in the presence and absence of an efflux pump inhibitor

\begin{tabular}{|c|c|c|c|c|c|c|c|c|c|c|c|c|}
\hline \multirow[t]{3}{*}{ Antibiotics } & \multicolumn{4}{|c|}{ S. Typhimurium (ATCC-14028) } & \multicolumn{4}{|c|}{ S. Typhimurium (LVPP-STI2) } & \multicolumn{4}{|c|}{ S. Typhimurium (LVPP-STI15) } \\
\hline & \multicolumn{2}{|l|}{ Pre } & \multicolumn{2}{|l|}{ Post } & \multicolumn{2}{|c|}{ Pre } & \multicolumn{2}{|l|}{ Post } & \multicolumn{2}{|c|}{ Pre } & \multicolumn{2}{|l|}{ Post } \\
\hline & WEI & $\mathrm{El}$ & WEI & $\mathrm{El}$ & WEI & El & WEI & El & WEI & $\mathrm{El}$ & WEI & $\mathrm{El}$ \\
\hline TET & 2 & 2 & 128 & 8 & 1 & 1 & 128 & 4 & 256 & 64 & 512 & 128 \\
\hline MBF & 0.03 & 0.03 & 0.06 & 0.06 & 0.03 & 0.03 & 0.06 & 0.03 & 0.5 & 0.13 & 2 & 0.26 \\
\hline FFL & 4 & 4 & 32 & 8 & 4 & 2 & 32 & 8 & 2 & 1 & 8 & 2 \\
\hline TMP & 0.04 & 0.04 & 0.04 & 0.04 & 0.04 & 0.04 & 0.16 & 0.16 & $>256$ & $>256$ & $>256$ & $>256$ \\
\hline STR & 32 & 32 & 512 & 64 & 1024 & 512 & 1024 & 1024 & 1024 & 1024 & $>1024$ & $>1024$ \\
\hline SMT & 64 & 64 & 64 & 64 & $>1024$ & 1024 & $>1024$ & $>1024$ & $>1024$ & $>1024$ & $>1024$ & $>1024$ \\
\hline TYL & 1024 & 512 & 1024 & 512 & 1024 & 1024 & 1024 & 1024 & 1024 & 1024 & 1024 & 1024 \\
\hline
\end{tabular}

SMX = sulfamethoxazole, TET = tetracycline, FFL = florfenicol, TMP = trimethoprim, MBF = marbofloxacin, STR = streptomycin, and TYL = tylosin, WEI = without the efflux pump inhibitor, El = together with the efflux pump inhibitor (Phe-Arg- $\beta$-naphthylamide, $40 \mu \mathrm{g} / \mathrm{mL}$ ). The MIC values were similar for both time points ( 12 vs $24 \mathrm{~h}$ ) 

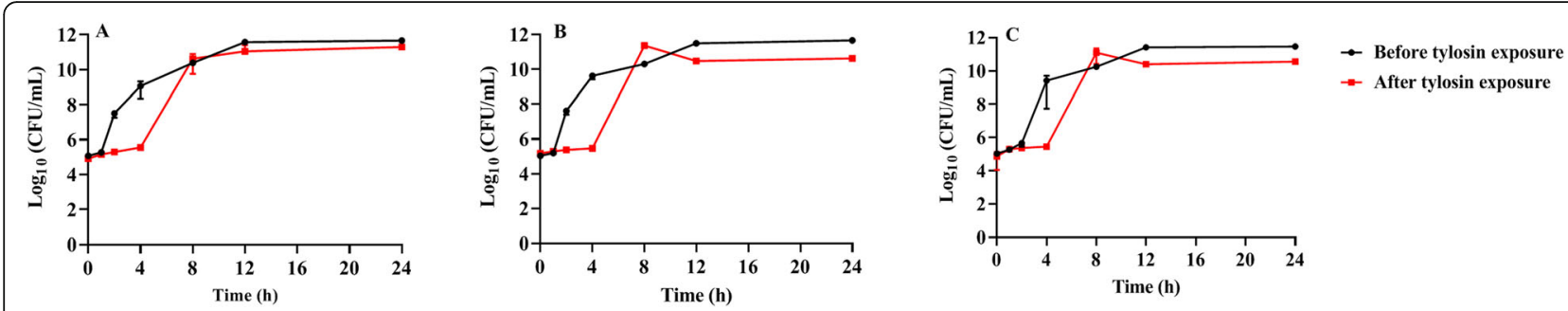

Fig. 1 The growth curves of S. Typhimurium ATCC14028 (a), LVPP-STI2 (b) and LVPP-STI15 (c) before and after exposure to decreasing concentration of tylosin (initial concentration of $3 \mu \mathrm{g} / \mathrm{mL}$ ) in the in vitro dynamic assay. There was not a time-dependent difference (12th vs 24 th h) in the growth curve of S. Typhimurium strains. Therefore, representative figures for both time points are displayed here

to 5.5 -fold $(P<0.01)$ and 5.9 -to 6.3 -fold $(P<0.001)$ increases in expression for the marA and sox $S$ genes, respectively in S. Typhimurium strains ATCC 14028 and LVPP-STI2 compared to the non-exposed counterparts. However, the changes in tylosin-induced expression of $\operatorname{ram} A$ (in all strains) and sox $S$ genes in $S$. Typhimurium LVPP-STI15 were not significant $(P<0.05)$. Tylosin exposure down-regulated expression of the ompC gene by 44.5-50.2\% $(P<0.05)$, while the change in ompF gene expression was insignificant $(P>0.05)$ (Fig. $3 g$ and $h$ )

\section{Discussion}

Only after a few years of initiation of antimicrobials use in humans, the selective pressure was identified as a driving force behind the emergence of resistant bacteria. Resistance is either genetically encoded which is then inherited by subsequent progeny of the resistant pathogens and in some cases could be transferred horizontally even to distantly related bacteria [11]. Acquisition of plasmid-mediated resistant genes is the principal mechanism for antimicrobial resistance in Salmonella. However, spontaneous gene mutation does contribute to the emergence of resistant Salmonella strains especially to quinolones $[12,13]$.

The selection of drug-resistant mutants at high antibiotic concentrations is a well-known fact. Exposure to high antibiotic concentrations exceeding the MIC interferes with the survival of susceptible bacteria, hence susceptible cells will no longer grow and are therefore outcompeted by resistant ones [14]. However, the role of exposure to antibiotics below their MIC has only recently gained importance in this context. Most importantly, the effects of sub-inhibitory concentrations of antibiotics in the evolution of resistant bacterial strains, especially to structurally unrelated antibiotics are less delineated. Exposure to sub-therapeutic doses of antibiotics may cause phenotypic and genetic variability and act as selectors of resistance [15]. The selection of antibiotic resistance at sub-inhibitory concentrations differs from that of the lethal drug concentration in various aspects. Selection at sub-inhibitory concentrations is progressive and is strongly associated with mutations that have a low fitness cost. In addition, it ensures greater mutational space and favors the accumulation of multiple small step mutations [15-17].

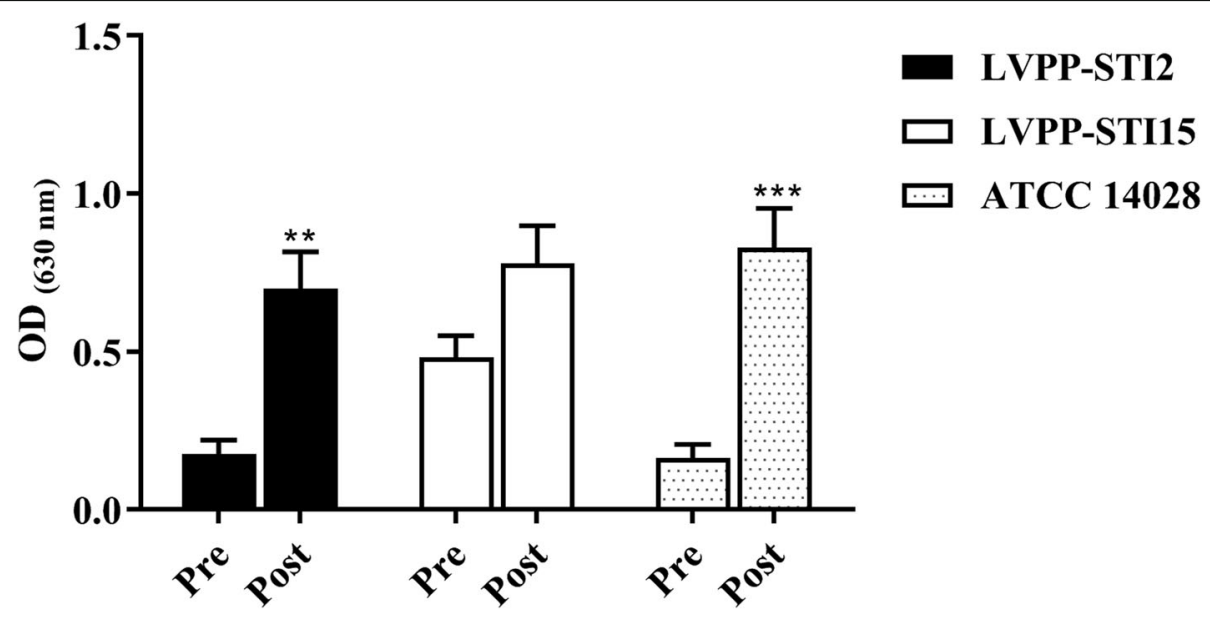

Fig. 2 Generation of free radicals (measured in terms of optical density) in S. Typhimurium before and after exposure to decreasing concentration of tylosin (initial concentration of $3 \mu \mathrm{g} / \mathrm{mL}$ ) in the in vitro dynamic assay. Data presented as mean \pm SD. ${ }^{*} P<0.01$ compared to the non-exposed S. Typhimurium 


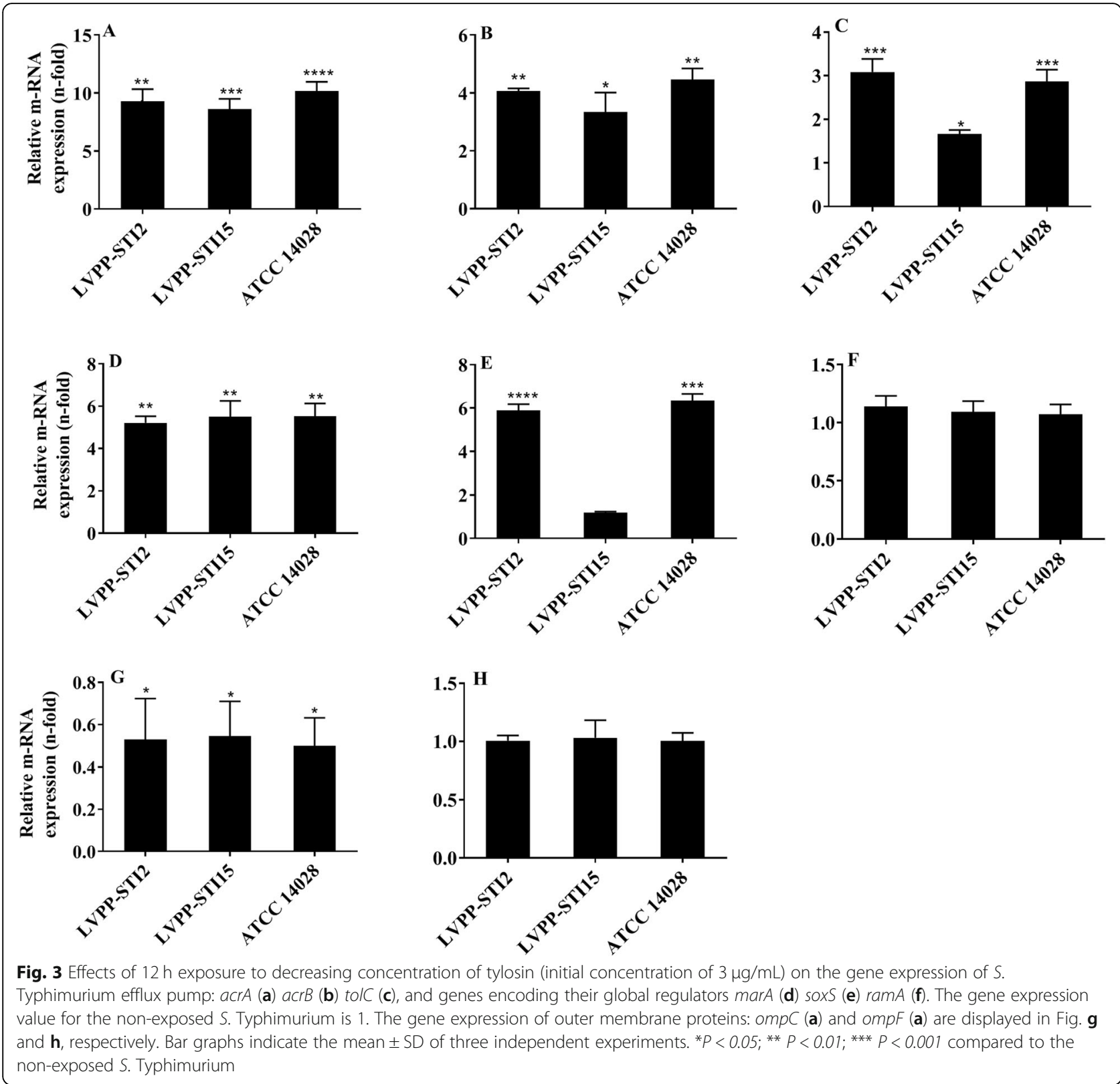

Tylosin has limited activity against Gram-negative bacteria, especially those belonging to the Enterobacteriaceae, because of reduced penetration of the outer membrane [4]. In this study, the MIC of tylosin against the tested $S$. Typhimurium strains was $1024 \mu \mathrm{g} / \mathrm{mL}$. In both the static and dynamic assays, Salmonella strains were exposed to $3 \mu \mathrm{g} / \mathrm{mL}$ of tylosin which is sub-lethal and had no impact on bacterial survival. It should also be taken into account that the concentration of tylosin in the dynamic model decreases through time from the initial $3 \mu \mathrm{g} / \mathrm{mL}$ because of the infusion of fresh medium and dilution of tylosin from the central compartment.

Previous studies have demonstrated that exposure to sub-MICs of antibiotics could lead to the emergence of multidrug-resistant strains through free radical (reactive oxygen species, ROS) induced mutagenesis [18]. In this study, we have observed that the levels of free radicals generated in tylosin exposed $S$. Typhimurium were significantly higher than the level in the non-exposed counterparts. Consistent with our findings, Kohanski et al. [19] demonstrated the association between the reduced susceptibility, antibiotics induce mutagenesis, and ROS generation in various bacteria, including E.coli following exposure to sub-lethal doses of antibiotics. Besides, a recent study by $\mathrm{Li}$ et al. [20] illustrated the generation of ROS and the subsequent emergence of vancomycinresistant Staphylococcus aureus after treatment with sub-MIC levels of vancomycin. 
Membrane permeability is one of the critical factors in regulating the antibiotic susceptibility of Enterobacteriaceae such as $S$. Typhimurium. Alteration of the bacterial envelope through the reduction of porin production or increased expression of efflux pump systems contributed significantly to the emergence of resistant bacteria [21]. Tetracyclines enter into $S$. Typhimurium via the outer membrane porins, OmpC or OmpF [22]. Therefore the interaction between the antibiotics and the bacterial target sites is dependent on the level of expression of these porins. This study demonstrated that the expression of ompC gene was significantly $(P<0.05)$ down-regulated following exposure to tylosin. Down-regulation of these porins reduces the diffusion of tetracyclines into the cytoplasm target sites and ultimately results in 6-to-18 fold increase in the MIC as reported in other Gramnegative bacteria. Besides, bacteria that acquire such type of resistance through suppression of porin could also become resistant to other antibiotics [23]. However, tylosin exposure did not produce a significant change in the expression of ompF gene $(P>0.05)$. The selective effect of tylosin on ompC gene expression is not surprising because previous studies in Gram-negative bacteria confirmed that the expression of these genes may vary depending upon the osmolarity of culture medium and type of chemical exposed [24, 25].

Activation of efflux pumps (acrAB-tolC) and reducing intracellular concentrations of tetracycline and florfenicol is the most familiar resistance mechanisms of Gramnegative bacteria [26]. The expression of $a c r A$, $a c r B$, and tolC was up-regulated to various extents in tylosin exposed $S$. Typhimurium strains with high MICs to florfenicol and tetracycline compared to the non-exposed counterparts. The decisive roles played by the AcrABTolC efflux system in acquiring multidrug resistance has also been explained by previous studies [27, 28]. Furthermore, the expression of the global regulators of acrA, $a c r B$, and tolC such as marA, and soxS were significantly up-regulated in tylosin-exposed $S$. Typhimurium strains compared to the non-exposed counterparts. Studies confirmed that these global regulators are critical for the activation of the transcription of acrA, acrB, and tolC $[29,30]$. This substantiates the role played by tylosin in activating the acrAB-tolC efflux system and its global regulators, which subsequently increases the MICs of florfenicol and tetracycline against $S$. Typhimurium. Therefore, reduced influx via altered porin phenotypes and simultaneous increased production of the AcrABtolC efflux pump and its global regulators could contribute to the higher MICs of florfenicol and tetracycline in $S$. Typhimurium strains pre-treated with tylosin.

Exposure to tylosin extended the lag-time of $S$. Typhimurium strains by approximately $2-2.5 \mathrm{~h}$. Most environmental strains of bacteria become resistant to the action of tetracycline by extending the lag-time [31]. Besides, a study by Fridman et al. [32] demonstrated that change in the lag-time is one of the most essential changes made by the bacterium to develop tolerance in response to antibiotic stress. Extension of lag-time is associated with the survival of bacteria in the presence of antibiotics beyond the MICs and subsequently facilitates the evolution of resistant bacteria. Moreover, the extension of the lag phase allows the bacteria to survive and regrow when optimal conditions arise. Overall, the differences in bacterial strains used in this study could contribute to the variations in the tylosin-induced changes in the MICs, free radical generation and gene expression in $S$. Typhimurium strains. Tylosin exposed $S$. Typhimurium strains exhibited similar MICs and gene expression patterns of efflux pumps following passage for multiple generations, indicating phenotypic and gene expression stability of the strains.

\section{Conclusions}

Exposure of $S$. Typhimurium to decreasing concentration of tylosin increases the MICs of florfenicol and tetracycline mainly through extending the lag phase of bacterial growth, enhancing ROS generation, and activating the acrAB-tolC efflux system. Future work will aim at investigating the molecular changes associated with the increased MICs florfenicol and tetracycline in tylosin-exposed $S$. Typhimurium.

\section{Methods}

\section{Chemicals and reagents}

The antibiotics, chemicals and reagents used in this study were purchased from Sigma (St. Louis, MO, USA) unless indicated. Stock solutions of florfenicol (FFL), sulfamethoxazole (SMX), tetracycline (TET) and trimethoprim (TMP) were prepared in dimethyl sulfoxide (DMSO). Marbofloxacin (MBF) and streptomycin (STR) were prepared in sterile distilled water. Besides, a stock solution of tylosin (TYL) was made in $50 \%$ ethanol. The stock preparations were diluted in sterile distilled water or appropriate broth medium. The concentrations of DMSO and ethanol in the final diluents never exceeded $0.1 \%(\mathrm{v} / \mathrm{v})$.

\section{S. Typhimurium strains and culture conditions}

$S$. Typhimurium strains (LVPP-STI2 and LVPP-STI15) isolated from swine [33] and $S$. Typhimurium ATCC14028 were cultured in Luria-Bertani (LB) - agar (Difco, MD, USA) at $37^{\circ} \mathrm{C}$. Before assays, the bacteria were grown overnight in LB-broth at $37^{\circ} \mathrm{C}$ in a shaking incubator. Our previous study revealed that the parent $S$. Typhimurium LVPP-STI15 possesses a single gyrA mutation resulting in amino acid substitution, Asp87Tyr, whereas no mutations were identified in the parent $S$. 
Typhimurium LVPP-STI2 [33]. In addition, our recent studies confirmed the invasive, quorum sensing and virulence potentials of these strains [34, 35].

\section{In vitro static tylosin therapy}

$S$. Typhimurium strains were cultured in $10 \mathrm{~mL}$ Mueller-Hinton broth (MHB) containing $3 \mu \mathrm{g} / \mathrm{mL}$ of tylosin and incubated at $37^{\circ} \mathrm{C}$ in a shaking incubator. The concentration of tylosin was determined based on the average results of the maximum plasma concentration of tylosin in swine from previous studies [36-38]. Twenty microliters of samples were taken at $0,1,2,4,6,8,12$ and $24 \mathrm{~h}$ from the time of incubation and cultured in LB-agar plates. The experiment was conducted in duplicate in three separate experiments.

\section{Tylosin therapy using the in vitro dynamic model}

A previously described in vitro dynamic model which contains a dilution compartment containing fresh MullerHinton broth II (MHB II), a central compartment with either a bacterial culture alone (control growth experiment) or a bacterial culture in medium containing tylosin (killingregrowth experiments), and an elimination compartment containing waste broth and bacteria was used to expose $S$. Typhimurium strains to tylosin [39]. A magnetic stirrer was placed in both flasks in the central compartment. Peristaltic pumps (Masterflex, Cole-Parmer, USA) circulated in one direction, from the dilution compartment to the central compartment and from the central compartment to the elimination compartment, at a flow rate of $8.1 \mathrm{~mL} / \mathrm{h}$ that corresponds to average half-life of tylosin in swine [36, 37]. The system was placed in an incubator at $37^{\circ} \mathrm{C}$. Six hundred microliter of an overnight culture of $S$. Typhimurium was inoculated into the central compartment. After $2 \mathrm{~h}$ of incubation, the bacterial cultures reached $10^{8} \mathrm{CFU} / \mathrm{mL}(6 \times$ $10^{9} \mathrm{CFU}$ per $60 \mathrm{~mL}$ central compartment). Tylosin $(3 \mu \mathrm{g} /$ $\mathrm{mL}$ ) was injected into one of the units in the central compartment. Then, $20 \mu \mathrm{L}$ aliquot samples were collected from each compartment in the central unit at $0,1,2.4,8,12$, and $24 \mathrm{~h}$. Samples were cultured on LB-agar plates and incubated at $37^{\circ} \mathrm{C}$ for $24 \mathrm{~h}$. The experiment was conducted in triplicate for each isolate.

\section{Determination of MIC in the presence and absence of an efflux pump inhibitor}

The minimum inhibitory concentration (MICs) of florfenicol, marbofloxacin, streptomycin, sulfamethoxazole, tetracycline and trimethoprim against $S$. Typhimurium strains were determined before and after (at $0,1,2,4,8,12$ and 24 $\mathrm{h}$ post-incubation) exposure to the static and dynamic tylosin treatment. The MICs were determined in the presence and absence of an efflux pump inhibitor (Phe-Arg- $\beta$ naphthylamide, $40 \mu \mathrm{g} / \mathrm{mL}$ ) using the broth microdilution method with an inoculum of approximately $10^{5} \mathrm{CFU} / \mathrm{mL}$.
Four colonies isolated from tylosin exposure/time point were assayed and this was repeated for three experiments i.e. a total of at least 12 colonies assayed for a single exposure/time point. The lowest concentrations of antibiotics inhibiting visible bacterial growth after incubation at $37^{\circ} \mathrm{C}$ for $18-24 \mathrm{~h}$ were considered as MICs. Clinical breakpoints for tetracycline, florfenicol and sulfamethoxazole were: TET $\geq 32 \mu \mathrm{g} / \mathrm{mL}, \quad F F L ~ \geq 16 \mu \mathrm{g} / \mathrm{mL}$ and SMT $\geq 512 \mu \mathrm{g} / \mathrm{mL}$. Since CLSI breakpoints were not available for marbofloxacin, streptomycin and trimethoprim, the following breakpoints were used: $\mathrm{MBF} \geq 1 \mu \mathrm{g} / \mathrm{mL}$ (ciprofloxacin), $\mathrm{STR} \geq$ $64 \mu \mathrm{g} / \mathrm{mL}$ and $\mathrm{TMP} \geq 2 \mu \mathrm{g} / \mathrm{mL}$ [40-42]. In addition, tylosin is known to be inactive against Gram-negative bacteria and its MIC in Salmonella is $\geq 1 \mathrm{mg} / \mathrm{mL}$ [34].

\section{Growth curves}

Based on the results of the MIC assay, the growth curves of $S$. Typhimurium strains were determined before and after exposure to tylosin for $12 \mathrm{~h}$ in the dynamic model. Briefly, $S$. Typhimurium $\left(10^{5} \mathrm{CFU} / \mathrm{mL}\right)$ was incubated at $37^{\circ} \mathrm{C}$ in $\mathrm{MH}$-broth in a shaking incubator. After $0,1,2$, $4,8,12$ and $24 \mathrm{~h}$ from the time of incubation, $100 \mu \mathrm{L}$ of the suspension was removed and diluted serially (10fold). Then, $20 \mu \mathrm{L}$ of the dilutions were spread plated on LB-agar plates and the CFUs were determined following incubation at $37^{\circ} \mathrm{C}$ for $24 \mathrm{~h}$.

\section{Estimation of free radicals}

NBT assay was performed to determine the amount of free radicals generated by $S$. Typhimurium before and after $(12 \mathrm{~h})$ exposure to tylosin using a minor modification of a previous method [11]. The quantity of formazan crystals that are produced from water-soluble tetrazolium salt within each bacterial cell is directly proportional to the production of free radicals [43]. Briefly, $4 \mathrm{~h}$ cultures of $S$. Typhimurium were diluted to $10^{6}$ $\mathrm{CFU} / \mathrm{mL}$ in LB-broth. Bacteria were centrifuged at 500 $\mathrm{x} g$ for $10 \mathrm{~min}$ and washed twice in $1 \times$ PBS. The pellet was then suspended in $1 \times$ PBS $(200 \mu \mathrm{L})$. Freshly prepared NBT $(0.01 \%)$ solution was added and incubated at $37^{\circ} \mathrm{C}$ for $1 \mathrm{~h}$. Then, it was washed again with $1 \times$ PBS and centrifuged at $500 \mathrm{xg}$ for $10 \mathrm{~min}$. The blue, waterinsoluble intracellular formazan crystals were dissolved in $60 \mu \mathrm{L}$ potassium hydroxide solution (2 M, DMSO). Thereafter, the preformed bacterial superoxide anions were quantified using a microplate reader at $630 \mathrm{~nm}$ (VersaMax, Molecular Devices, CA, USA). The experiment was conducted in duplicate in three different experiments for each strain.

\section{QRT-PCR analysis of Salmonella efflux pump, the efflux pump global regulators, and outer membrane porins} Quantitative reverse transcription-PCR (qRT-PCR) analysis was performed to determine the impacts of tylosin 
exposure $(12 \mathrm{~h})$ on the gene expression of $\operatorname{acr} A, \operatorname{acr} B$, and tolC (encoding the $S$. Typhimurium AcrAB-TolC efflux pump), marA, soxS, and $\operatorname{ram} A$ (encoding their global regulators), and $o m p C$ and $o m p F$ (encoding outer membrane porins). Total RNA was extracted using TRIzol (Ambion Life Technologies, Carlsbad, CA, USA) and qRT-PCR was conducted similarly to O'Regan et al. [29]. Gene expression levels of $a c r A$, acrB, and tolC, marA, soxs, $\operatorname{ram} A, \quad$ ompC and ompF were determined by CFX96 Touch ${ }^{\text {Tw }}$ real-time PCR detection system (174 Biorad, USA) using $\mathrm{IQ}^{\text {mix }}$ SYBR $^{\circ}$ Green Supermix (Biorad, Singapore). The reaction conditions include denaturation at $94{ }^{\circ} \mathrm{C}$ for $3 \mathrm{~min}$, followed by 35 cycles of amplification. Each cycle of amplification consists of $1 \mathrm{~min}$ at $94{ }^{\circ} \mathrm{C}, 20-60 \mathrm{~s}$ at the appropriate annealing temperature (Additional file 2), and $1 \mathrm{~min}$ at $72^{\circ} \mathrm{C}$. The final extension step was at $72{ }^{\circ} \mathrm{C}$ for $10 \mathrm{~min}$. The housekeeping gene $\operatorname{rrs} G$ was used to normalize gene expression $\left(2^{-\Delta \Delta C T}\right)$. The primers used in this experiment are listed in Additional file 2.

\section{Data analysis}

Data were analyzed using GraphPad Prism 6 (GraphPad Software, Inc., San Diego, CA, USA). One-way analyses of variance (ANOVA) followed by Tukey's HSD test were conducted to compare the mean values among treatment groups. $p<0.05$ was considered statistically significant.

\section{Supplementary information}

Supplementary information accompanies this paper at https://doi.org/10 1186/s12917-020-2246-5.

Additional file 1: Table S1. The MICs $(\mu \mathrm{g} / \mathrm{mL})$ of selected antibiotics against $\mathrm{S}$. Typhimurium strains before and after exposure to tylosin (taken after 1 and $2 \mathrm{~h}$ of incubation in the in vitro dynamic model and at all tylosin exposure/time points in the static model) in the presence and absence of an efflux pump inhibitor. Table S2. The MICs $(\mu \mathrm{g} / \mathrm{mL})$ of selected antibiotics against $\mathrm{S}$. Typhimurium strains before and after exposure to tylosin (taken after 4 and $8 \mathrm{~h}$ of incubation) in the in vitro dynamic model and in the presence and absence of an efflux pump inhibitor

Additional file 2. Lists of primer sequences.

\section{Abbreviations}

ANOVA: Analysis of variance; CFU: Colony-forming unit; LB: Luria-Bertani; MHB: Mueller-Hinton broth; MIC: Minimum inhibitory concentration; qRTPCR: quantitative real-time reverse transcription PCR; ROS: Reactive oxygen species

\section{Acknowledgments}

We thank members of Laboratory of Veterinary Pharmacokinetics and Pharmacodynamics at the College of Veterinary Medicine, Kyungpook National University, for their technical support.

\section{Authors' contributions}

AFM was involved in conceptualization, data acquisition, analysis, interpretation and writing the original draft. SCP participated in the conceptualization, supervision and review of the manuscript. Both the authors critically revised and approved the final version of the manuscript.

\section{Funding}

This study was financially supported by the National Research Foundation of Korea (NRF) (2019R1A2C2006277) and in part by the ministry of small and medium-sized enterprises (SMEs) and Startups (MSS), Korea, under the regional specialized industry develpoment program ( $R$ and D, P0002954) supervised by the Korea Institute for Advancement of Technology (KAT). The funders had no role in study design, data collection and interpretation, or the decision to submit the work for publication. The manuscript was based, in part, on the first author's doctoral dissertation at Kyungpook National University.

\section{Availability of data and materials}

All data generated or analyzed during this study are included in this published article.

Ethics approval and consent to participate

Not applicable

\section{Consent for publication}

Not applicable

\section{Competing interests}

The authors declare that they have no competing interests.

Received: 21 September 2019 Accepted: 16 January 2020

Published online: 28 January 2020

\section{References}

1. Hohmann EL. Nontyphoidal Salmonellosis. Clin Infect Dis. 2001;32:263-9.

2. Funk J, Wa G. Risk factors associated with Salmonella prevalence on swine. J Swine Heal Prod. 2004:12:246-51.

3. Letellier A, Messier S, Paré J, Paré J, Ménard J, Quessy S. Distribution of Salmonella in swine herds in Quebec. Vet Microbiol. 1999;67:299-306.

4. Dibner JJ, Richards JD. Antibiotic growth promoters in agriculture: history and mode of action. Poult Sci. 2005:634-43.

5. Kim J, Guevarra RB, Nquyen SG, Lee JH, Jeong DK, Unno T. Effects of the antibiotics growth promoter tylosin on swine gut microbiota. J Microbol Biotechnol. 2016;26:876-82.

6. Couce A, Blázquez J. Side effects of antibiotics on genetic variability. FEMS Microbiol Rev. 2009;33:531-8.

7. Aarestrup FM, Carstensen B. Effect of tylosin used as a growth promoter on the occurrence of macrolide-resistant enterococci and staphylococci in pigs. Microb Drug Resist. 1998;4:307-12.

8. Fung-Tomc J, Kolek B, Bonner DP. Ciprofloxacin-induced, low-level resistance to structurally unrelated antibiotics in Pseudomonas aeruginosa and methicillin-resistant Staphylococcus aureus. Antimicrob Agents Chemother. 1993;37:1289-96.

9. Chen L, He S, Li C, Ryu J. Sublethal kanamycin induced cross-resistance to functionally and structurally unrelated antibiotics. J Exp Microbiol Immuno. 2009;13:53-7.

10. Henderson-Begg SK, Livermore DM, Hall LMC. Effect of subinhibitory concentrations of antibiotics on mutation frequency in Streptococcus pneumoniae. J Antimicrob Chemother. 2006;57:849-54.

11. Frey JG, Jackson CR. Genetic mechanisms of antimicrobial resistance identified in Salmonella enterica, Escherichia coli, and Enterococcus spp. isolated from U.S. food animals. Front Microbiol. 2013;4:135.

12. Campioni F, Souza RA, Martins W, Stehling EG, Bergamini AMM, Falcao JP. Prevalence of gyrA mutations in nalidixic acid-resistant strains of Salmonella Enteritidis isolated from humans, food, chickens, and the farm environment in Brazil. Microb Drug Resist. 2017;23:421-8.

13. Saenz $Y$, Zarazaga M, Brinas L, Ruiz-Larrea F, Torres C. Mutations in gyrA and parC genes in nalidixic acid-resistant strains from food products, humans and animals. J Antimicrob Chemother. 2003:51:1001-5.

14. Drlica K. The mutant selection window and antimicrobial resistance. J Antimicrob Chemother. 2003;52:11-7.

15. Andersson DI, Hughes D. Microbiological effects of sublethal levels of antibiotics. Nat Rev Microbiol. 2014;12:465-78.

16. Andersson DI, Hughes D. Evolution of antibiotic resistance at non-lethal drug concentrations. Drug Resist Updat. 2012;15:162-72.

17. Mao EF, Alne L, Lee J, Miller JH. Proliferation of mutators in a cell population. J Bacteriol. 1997;179:417-22. 
18. Bhattacharya G, Dey D, Das S, Banerjee A. Exposure to sub-inhibitory concentrations of gentamicin, ciprofloxacin and cefotaxime induces multidrug resistance and reactive oxygen species generation in meticillinsensitive Staphylococcus aureus. J Med Microbiol. 2017:66:762-9.

19. Kohanski MA, DePristo MA, Collins JJ. Sublethal antibiotic treatment leads to multidrug resistance via radical-induced mutagenesis. Mol Cell. 2010;37:311-20.

20. Li G, Quan F, Qu T, Lu J, Chen S, Cui L, et al. Sublethal vancomycin-induced ROS mediating antibiotic resistance in Staphylococcus aureus. Biosci Rep. 2015;35:e00279

21. James C, Bolla JM, Pages JM, Molitor A, Garnotel E, Davin-Regli A. Membrane permeability and regulation of drug "influx and efflux" in enterobacterial pathogens. Curr Drug Targets. 2008;9:750-9.

22. Schnappinger D, Hillen W. Tetracyclines: antibiotic action, uptake, and resistance mechanisms. Arch Microbiol. 1996;165:359-69.

23. Cohen SP, McMurry LM, Hooper DC, Wolfson JS, Levy SB. Cross-resistance to fluoroquinolones in multiple-antibiotic-resistant (mar) Escherichia coli selected by tetracycline or chloramphenicol: decreased drug accumulation associated with membrane changes in addition to OmpF reduction Antimicrob Agents Chemother. 1989;33:1318-25.

24. Choi KM, Kim MH, Cai H, Lee YJ, Hong Y, Ryu PY. Salicylic acid reduces ompF expression, rendering Salmonella enterica serovar Typhimurium more resistant to cephalosporin antibiotics. Chonnam Med J. 2018;54:17-23.

25. Srividhya KV, Krishnaswamy S. A simulation model of Escherichia coli osmoregulatory switches using E-CELL system. BMC Microbiol. 2004;4:44.

26. Giraud E, Cloeckaert A, Kerboeuf D, Chaslus-Dancla E. Evidence for active efflux as the primary mechanism of resistance to ciprofloxacin in Salmonella enterica serovar Typhimurium. Antimicrob Agents Chemother. 2000;44:1223-8.

27. Baucheron S, Tyler S, Boyd D, Mulvey MR, Chaslus-Dancla E, Cloeckaert A. AcrAB-TolC directs efflux-mediated multidrug resistance in Salmonella enterica serovar Typhimurium DT104. Antimicrob Agents Chemother. 2004; 48:3729-35.

28. Olliver A, Vallé M, Chaslus-Dancla E, Cloeckaert A. Role of an acrR mutation in multidrug resistance of in vitro-selected fluoroquinolone-resistant mutants of Salmonella enterica serovar Typhimurium. FEMS Microbiol Lett. 2004;238:267-72.

29. O'Regan E, Quinn T, Pages JM, McCusker M, Piddock L, Fanning S. Multiple regulatory pathways associated with high-level ciprofloxacin and multidrug resistance in Salmonella enterica serovar enteritidis: involvement of ramA and other global regulators. Antimicrob Agents Chemother. 2009:53:1080-7.

30. Ferrari RG, Galiana A, Cremades R, Rodríguez JC, Magnani M, Tognim MCB, et al. Expression of the marA, soxS, acrB and ramA genes related to the AcrAB/TolC efflux pump in Salmonella enterica strains with and without quinolone resistance-determining regions gyrA gene mutations. Brazilian J Infect Dis. 2013;17:125-30.

31. Li B, Qiu Y, Shi H, Yin H. The importance of lag time extension in determining bacterial resistance to antibiotics. Analyst. 2016;141:3059-67.

32. Fridman O, Goldberg A, Ronin I, Shoresh N, Balaban NQ. Optimization of lag time underlies antibiotic tolerance in evolved bacterial populations. Nature. 2014;513:418-21

33. Lee SJ, Park NH, Mechesso AF, Lee KJ, Park SC. The phenotypic and molecular resistance induced by a single-exposure to sub-mutant prevention concentration of marbofloxacin in Salmonella Typhimurium isolates from swine. Vet Microbiol. 2017:207:29-35.

34. Mechesso AF, Yixian Q, Park SC. Methyl gallate and tylosin synergistically reduced the membrane integrity and intracellular survival of Salmonella Typhimurium. PLoS One. 2019;14:E0221386.

35. Mechesso AF, Yixian Q, Park SC. Ginsenoside Rg3 reduces the adhesion, invasion and intracellular survival of Salmonella enterica serovar Typhimurium. JGR. 2019. https://doi.org/10.1016/j.jgr.2019.09.002.

36. Huang L, Zhang H, Li M, ljaz A, Wang Y, Yuan Z. Pharmacokineticpharmacodynamic modeling of tylosin against Streptococcus suis in pigs. BMC Vet Res. 2018;14:319.

37. Kim MH, Gebru E, Chang ZQ, Choi JY, Hwang MH, Kang EH, et al. Comparative pharmacokinetics of tylosin or florfenicol after a single intramuscular administration at two different doses of tylosin-florfenicol combination in pigs. J Vet Med Sci. 2008;70:99-102.

38. Prats C, El Korchi G, Francesch R, Arboix M, Pérez B. Disposition kinetics of tylosin administered intravenously and intramuscularly to pigs. Res Vet Sci. 2002;73:141-4

39. Lee SJ, Awji EG, Park NH, Park SC. Using in vitro dynamic models to evaluate fluoroquinolone activity against emergence of resistant Salmonella enterica serovar Typhimurium. Antimicrob Agents Chemother. 2017;61: e01756-16.

40. Clinical and Laboratory Standards Institute. Performance standards for antimicrobial disk and dilution susceptibility tests for bacteria isolated from animals: approved standard- fourth edition. Wayne: VET01-A4 CLSI; 2013.

41. Clinical and Laboratory Standards Institute. Performance standards for antimicrobial susceptibility testing; twenty-fifth informational supplement. Wayne: Development M100-S25 CLSI; 2015.

42. National Antimicrobial resistance monitoring system for enteric bacteria (NARMS). Human isolates Final report, 2010. Atlanta: U. S. Department of health and human services. CDC; 2012

43. Esfandiari N, Sharma RK, Saleh RA, Thomas AJ, Agarwal A. Utility of the Nitroblue Tetrazolium reduction test for assessment of reactive oxygen species production by seminal leukocytes and spermatozoa. J Androl. 2003; 24:862-70.

\section{Publisher's Note}

Springer Nature remains neutral with regard to jurisdictional claims in published maps and institutional affiliations.

Ready to submit your research? Choose BMC and benefit from:

- fast, convenient online submission

- thorough peer review by experienced researchers in your field

- rapid publication on acceptance

- support for research data, including large and complex data types

- gold Open Access which fosters wider collaboration and increased citations

- maximum visibility for your research: over $100 \mathrm{M}$ website views per year

At $\mathrm{BMC}$, research is always in progress.

Learn more biomedcentral.com/submissions 